Check for updates

Cite this: RSC Adv., 2018, 8, 24411

\title{
ZnS coating for enhanced environmental stability and improved properties of $\mathrm{ZnO}$ thin films
}

\author{
Anna Baranowska-Korczyc, (D) *a Mikołaj Kościński, ${ }^{\text {ab }}$ Emerson L. Coy, (D) a \\ Bartosz F. Grześkowiak, ${ }^{2}$ Małgorzata Jasiurkowska-Delaporte, (D) ac \\ Barbara Peplińska ${ }^{a}$ and Stefan Jurga (D) ${ }^{a}$
}

\begin{abstract}
Low environmental stability of $\mathrm{ZnO}$ nanostructures in hydrophilic systems is a crucial factor limiting their practical applications. ZnO nanomaterials need surface passivation with different water-insoluble compounds. This study describes a one-step passivation process of polycrystalline $\mathrm{ZnO}$ films with $\mathrm{ZnS}$ as a facile method of $\mathrm{ZnO}$ surface coating. A simple sulfidation reaction was carried out in gas-phase $\mathrm{H}_{2} \mathrm{~S}$ and it resulted in formation of a $\mathrm{ZnS}$ thin layer on the $\mathrm{ZnO}$ surface. The $\mathrm{ZnS}$ layer not only inhibited the $\mathrm{ZnO}$ dissolving process in water but additionally improved its mechanical and electrical properties. After the passivation process, $\mathrm{ZnO} / \mathrm{ZnS}$ films remained stable in water for over seven days. The electrical conductivity of the $\mathrm{ZnO}$ films increased about 500 -fold as a result of surface defect passivation and the removal of oxygen molecules which can trap free carriers. The nanohardness and Young's modulus of the samples increased about $64 \%$ and $14 \%$, respectively after the ZnS coating formation. Nanowear tests performed using nanoindentation methods revealed reduced values of surface displacements for the $\mathrm{ZnO} / \mathrm{ZnS}$ system. Moreover, both $\mathrm{ZnO}$ and $\mathrm{ZnO} / \mathrm{ZnS}$ films showed antimicrobial properties against Escherichia coli.
\end{abstract}

Received 1st April 2018

Accepted 2nd July 2018

DOI: $10.1039 / \mathrm{c} 8 \mathrm{ra0} 2823 \mathrm{k}$

rsc.li/rsc-advances passivation by $\mathrm{ZnS}$, shallow defects such as surface oxygen vacancies are removed, which significantly improves the optical and electrical properties of the material. The $\mathrm{ZnS}$ coating also protects the surface of $\mathrm{ZnO}$ against environmental influences. The oxygen molecules are able to interact with free electrons and do not modulate the level of free carriers in the nanostructures.

Although there are many different methods of $\mathrm{ZnO}$ surface passivation by $\mathrm{ZnS}$, most are carried out at high temperature and high pressure. The $\mathrm{ZnS}$ passivation layer formed at room temperature in a one-step process is more unique. In the traditional approaches, $\mathrm{ZnO} / \mathrm{ZnS}$ films have been prepared by magnetron sputtering deposition, ${ }^{8}$ and powders by the microwave-assisted solvothermal method. ${ }^{9}$ Core/shell $\mathrm{ZnO} / \mathrm{ZnS}$ nanowires have been obtained by sulfurizing $\mathrm{ZnO}$ nanowires using a vapor phase method under 23 torr and sulfur powder at a temperature of $190{ }^{\circ}$ C. $^{10} \mathrm{ZnO}$ nanorods have been sulfided by $\mathrm{Na}_{2} \mathrm{~S}$ aqueous solution or immersed in alcoholic solutions of $2 \mathrm{~nm} \mathrm{ZnS} \mathrm{quantum}$ dots. ${ }^{11}$ In other studies, ZnO nanofibers have been covered by a ZnS shell during a gas-phase sulfidation reaction with hydrogen sulfide $^{\mathbf{1 2}}$ and sputtered $\mathrm{ZnO}$ films have been coated or totally converted to ZnS films by a sulfidation process. ${ }^{13}$

Coating with ZnS results in significant changes in the physicochemical properties of the $\mathrm{ZnO}$ nanostructures. It has been observed that $\mathrm{ZnO} / \mathrm{ZnS}$ nanotube arrays possess higher conductivity and better photoresponse than $\mathrm{ZnO}$ nanotube arrays due to the fact that the type-II band gap alignment in $\mathrm{ZnO} / \mathrm{ZnS}$ facilitates the transfer of photoexcited electrons from the conduction band of $\mathrm{ZnS}$ to that of $\mathrm{ZnO}$; the photoexcited
${ }^{a}$ NanoBioMedical Centre, Adam Mickiewicz University, Umultowska 85, PL-61614 Poznań, Poland. E-mail: akorczyc@chem.uw.edu.pl

${ }^{b}$ Department of Physics and Biophysics, Poznan University of Life Sciences, Wojska Polskiego 38/42, PL-60637 Poznań, Poland

${ }^{c}$ The Henryk Niewodniczański Institute of Nuclear Physics, Polish Academy of Sciences, Radzikowskiego 152, 31-342 Kraków, Poland 
holes in the $\mathrm{ZnO}$ valence band are injected to the valence band of $\mathrm{ZnS}^{14}$ The $\mathrm{ZnS} / \mathrm{ZnO}$ nanocomposite shows good $\mathrm{H}_{2}$ evolution activity and stability without any co-catalyst, and superior catalytic performance in sunlight-driven $\mathrm{H}_{2} \cdot{ }^{15}$ It was also noted that $\mathrm{ZnO} / \mathrm{ZnS}$ heterostructured nanorods exhibit much better performance in photocatalytic hydrogen evolution than $\mathrm{ZnO}$ and 1D ZnS nanorods. ${ }^{16}$ Similarly, $\mathrm{ZnO} / \mathrm{ZnS}$ nanocable and nanotube arrays demonstrate much higher photodegradation efficiency than $\mathrm{ZnO}$ nanowire arrays, ${ }^{3}$ and $\mathrm{ZnO} / \mathrm{ZnS}$ nanorods exhibit a specific capacitance of $217 \mathrm{mF} \mathrm{cm}^{-2}$ at $1 \mathrm{~mA} \mathrm{~cm}^{-2}$ which is superior to pure $\mathrm{ZnO}$ and $\mathrm{ZnS}$ nanostructures. ${ }^{17}$

The properties of the $\mathrm{ZnO} / \mathrm{ZnS}$ type-II heterojunction enable the construction of various devices and broaden the range of applications for the two materials. High-performance broad ultraviolet photodetectors have been fabricated on $\mathrm{ZnO} / \mathrm{ZnS}$ core/shell nanowires ${ }^{\mathbf{1 8}}$ and flexible branched $\mathrm{ZnS} / \mathrm{ZnO}$ nanofilms. ${ }^{7}$ A flexible robust sensor with $\mathrm{ZnO} / \mathrm{ZnS}$ core-shell nanoarrays was constructed to detect $\mathrm{Pb}^{2+}$ ions for potential applications in environmental protection and pollutant surveillance. ${ }^{19} \mathrm{ZnO}$ nanorods covered with $\mathrm{ZnS}$ shell showed improved photocatalytic activity for antibiotics degradation. ${ }^{20}$ The presence of sulfur on the nanomaterial surface can facilitate further biofunctionalization and the preparation of biodetectors such as protein sensors based on $\mathrm{ZnO} / \mathrm{ZnS}$ nanofibers. ${ }^{12}$ In addition, an amperometric cholesterol biosensor has been constructed based on enzyme-immobilized microtubular ZnO@ZnS heterostructures. ${ }^{21}$

There is no doubt that the $\mathrm{ZnO} / \mathrm{ZnS}$ heterostructure combines the advantageous properties of both nanomaterials. This issue has been addressed in many reports in recent years. However, there is still a huge demand for the simple methods of $\mathrm{ZnO} / \mathrm{ZnS}$ type-II heterojunction formation.

In this report, we introduce a simple concept of one-step passivation process of $\mathrm{ZnO}$ nanolayer carried out in a gas-phase method. A facile sulfidation reaction results in the formation of thin chemically stable ZnS layer on ZnO surface. This concept can help to overcome problems related to practical applications of $\mathrm{ZnO}$ nanostructures, for example, solubility in biological liquids. The synthesized $\mathrm{ZnO} / \mathrm{ZnS}$ film can potentially offer a multifunctional base for designing various devices due to the fact that $\mathrm{ZnO}$ passivation with $\mathrm{ZnS}$ provides a new system characterized by high stability in a hydrophilic environment as well as improved mechanical and electrical properties. Moreover, antibacterial properties of $\mathrm{ZnO}$ remain unchanged after $\mathrm{ZnS}$ passivation process and even slightly improved, which can enhance their future potential for biological and medical applications.

\section{Experimental}

\section{Synthesis of $\mathrm{ZnO}$ and $\mathrm{ZnO} / \mathrm{ZnS}$ nanolayers}

The ZnO nanolayers were synthesized by a spin-coating process using an aqueous solution of poly(vinyl alcohol) (PVA, $M_{\mathrm{w}}$ of $72000 \mathrm{Da}$ ) and zinc acetate dihydrate. The PVA mixture was prepared in water at $7.7 \%$ wt concentration. Following this, $0.25 \mathrm{~g}$ of zinc acetate was added to $1.25 \mathrm{~g}$ of polymer. The homogenous solution was spin-coated at $3000 \mathrm{RPM}$ for $30 \mathrm{~s}$. The single nanolayer was synthesized from $50 \mu \mathrm{l}$ of the solution using $10 \mathrm{~mm} \times 10 \mathrm{~mm}$ silicon $(\mathrm{Si})$ substrates. The nanolayers were calcined in air at $500{ }^{\circ} \mathrm{C}$ for two hours to obtain polycrystalline $\mathrm{ZnO}^{22}$ The samples were also prepared on Si covered with $300 \mathrm{~nm}$ thick silicon dioxide $\left(\mathrm{SiO}_{2}\right)$ layer and quartz glass for electrical and antimicrobial properties studies, respectively. Different substrates were applied due to the fact that $\mathrm{ZnO}$ crystal morphology was not affected by the substrate effect at the selected temperature of calcination.

The ZnO nanolayers were placed into a hermetic chamber with a volume of $50 \mathrm{ml}$ in the presence of $4 \mathrm{ml}$ of $20 \%$ aqueous solution of $\left(\mathrm{NH}_{4}\right)_{2} \mathrm{~S}$. The nanolayers were exposed to decomposition products of ammonium sulfide for three hours. ${ }^{23}$ The ZnS nanolayers were synthesized on the ZnO surfaces as a result of the sulfidation process. A detailed description of the synthesis of the $\mathrm{ZnO}$ and $\mathrm{ZnO} / \mathrm{ZnS}$ nanolayers is given in our previous study. ${ }^{24}$

\section{Characterization of the nanolayers}

The topography and roughness of $\mathrm{ZnO}$ and $\mathrm{ZnO} / \mathrm{ZnS}$ nanofilms were studied by Atomic Force Microscopy (AFM, Icon Bruker). AFM measurements were performed with tapping mode and MESP Brucker probes covered with a conductive alloy of cobalt and chromium (CoCr). The AFM measurements were performed at $0.2 \mathrm{~Hz}$ with 512 probe scans for a single image.

The chemical composition of the nanofilms was investigated by Energy Dispersive X-ray spectroscopy (EDX, Jeol 7001TTLS). Structural characterization of the layers was performed by Glazing incident X-ray diffraction (GI-XRD) using a highresolution powder diffractometer ( $\mathrm{X}^{\prime}$ pert $^{3}-\mathrm{MRD}$, PANalytical) employing $\mathrm{CuK}_{\alpha 1}$ radiation; the incident angle was $2^{\circ}$ and the diffractometer parameters were $45 \mathrm{kV}$ and $45 \mathrm{~mA}$. Fourier transform infrared spectroscopy (FTIR) and Raman spectroscopy were also used to analyze the structure of $\mathrm{ZnO}$ and $\mathrm{ZnO} /$ ZnS samples. The infrared spectra were recorded by a BRUKER Tensor 27 Fourier Transform Infrared (FTIR) spectrometer using a diamond Attenuated Total Reflection (ATR) accessory. FTIR absorption spectra were measured in the wavenumber range 400 to $3500 \mathrm{~cm}^{-1}$ with a resolution of $4 \mathrm{~cm}^{-1}$. The Raman spectra were examined using an inVia Ranishaw Raman Microscopy System (Ranishaw, Old Town, Wotton-under-Edge, UK). The excitation source was an Ar laser $(488 \mathrm{~nm})$. Each spectrum was collected with five accumulations in the wavenumber range of 200 to $800 \mathrm{~cm}^{-1}$.

The nanohardness and elastic modulus of the samples were measured by nanoindentation (Hysitron TI 950 TriboIndenter) using a Berkovich diamond tip with a maximum penetration depth below $300 \mathrm{~nm}$ at room temperature. Hardness and elastic modulus values were determined from load-displacement curves by the Oliver-Pharr method. ${ }^{25}$ Samples were scanned under very low force settings to avoid displacements during the topographic survey. Nanowear tests were performed by holding a constant force of 25 and $50 \mu \mathrm{N}$ and then calculating the displaced material by the residual imprint in Gwydion software.

In order to study the stability of the films before and after the sulfidation process, they were immersed in water for seven days. After ZnO nanofilm synthesis process, each sample was cut into 
four pieces. Two pieces were treated with $\mathrm{H}_{2} \mathrm{~S}$. As a result, two samples of $\mathrm{ZnO}$ and two samples of $\mathrm{ZnO} / \mathrm{ZnS}$ nanofilms were obtained. One piece of $\mathrm{ZnO}$ sample and one with the $\mathrm{ZnO} / \mathrm{ZnS}$ nanofilm were immersed in DI water for seven days, while the two remaining samples were not treated with any liquids (control samples). The dissolution process was observed using SEM (Scanning Electron Microscopy, Jeol 7001TTLS) images of each sample.

To study the electrical signal of the $\mathrm{ZnO}$ and $\mathrm{ZnO} / \mathrm{ZnS}$ nanolayers, Conductive-AFM (C-AFM) analysis was performed using contact mode AFM (Bruker's INNOVA) and probes (SCMPIC Bruker) covered with platinum and iridium alloy (Pt/Ir). During the measurement, a constant voltage of $0.5 \mathrm{~V}$ was applied to the layer. C-AFM signal was manually controlled by the Variable Gain Low Noise Current DLPCA-200 amplifier. The topography and C-AFM maps were scanned at the same time. The AFM measurements were obtained at a frequency of $0.1 \mathrm{~Hz}$ and 512 probe scans for each AFM image.

The electrical conductivity of the $\mathrm{ZnO}$ nanofilms before and after the sulfidation process was also measured using Van der Pauw method with a four-point probe placed at the corner of each sample. The measurements were performed using a Keithley 2400 source meter. The samples for C-AFM and conductivity measurements were prepared on $10 \times 10 \mathrm{~mm}$ silicon substrates covered with a $300 \mathrm{~nm}$ silicon dioxide $\left(\mathrm{SiO}_{2}\right)$ layer.

The antibacterial activities of the $\mathrm{ZnO}$ and $\mathrm{ZnO} / \mathrm{ZnS}$ films against Escherichia coli (E. coli, DH5 $\alpha$ ) bacteria were studied using the antibacterial drop-test. ${ }^{26,27}$ The bacterial cells were cultured in $5 \mathrm{ml}$ of Luria broth in a sterile $15 \mathrm{ml}$ conical tube. The culture was incubated at $37^{\circ} \mathrm{C}$ while being shaken at 220 RPM (MaxQ600 Shaker, Thermo Scientific) for 18-20 hours. The culture was then washed twice with sterilized saline $(0.9 \% \mathrm{NaCl})$ solution by centrifuging at $4000 \mathrm{rpm}$ for 10 minutes and then the cell pellet was re-suspended in sterilized saline solution. The samples were placed in Petri dish and $50 \mu \mathrm{l}$ of $0.9 \% \mathrm{NaCl}$ solution containing about $10^{9}$ colony forming units (CFU) was added drop-wise onto the surface of a $\mathrm{ZnO}$ or $\mathrm{ZnO} / \mathrm{ZnS}$ nanofilm synthesized on $10 \times 10 \mathrm{~mm}$ quartz glass. Pure glass substrate without any film was used as a control sample. After four hours of incubation at RT, the samples were suspended in $3 \mathrm{ml}$ of saline solution in $50 \mathrm{ml}$ conical tubes and shaken at $300 \mathrm{RPM}$ for $15 \mathrm{~min}$. Serial dilutions were prepared by taking $100 \mu \mathrm{l}$ of the previous solution and mixed with $900 \mu \mathrm{l}$ of $0.9 \% \mathrm{NaCl}$. From this solution, $100 \mu \mathrm{l}$ was plated onto the triplicate solid agar using the spread plate method. After incubation for 24 hours at $37^{\circ} \mathrm{C}$, the number of surviving bacterial colonies on the Petri dishes was counted and the survival ratio of bacteria was defined as the percentage of viable bacteria on the analyzed samples in comparison to a viable number of the bacteria on the control sample. Results are given as mean \pm SD of triplicates from three separate experiments.

\section{Results and discussion}

Examination of the ZnO nanofilms before and after the sulfidation process reveal that they consist of crystals measuring tens of nanometers, which are visible by SEM (Fig. 1(a) and (b))
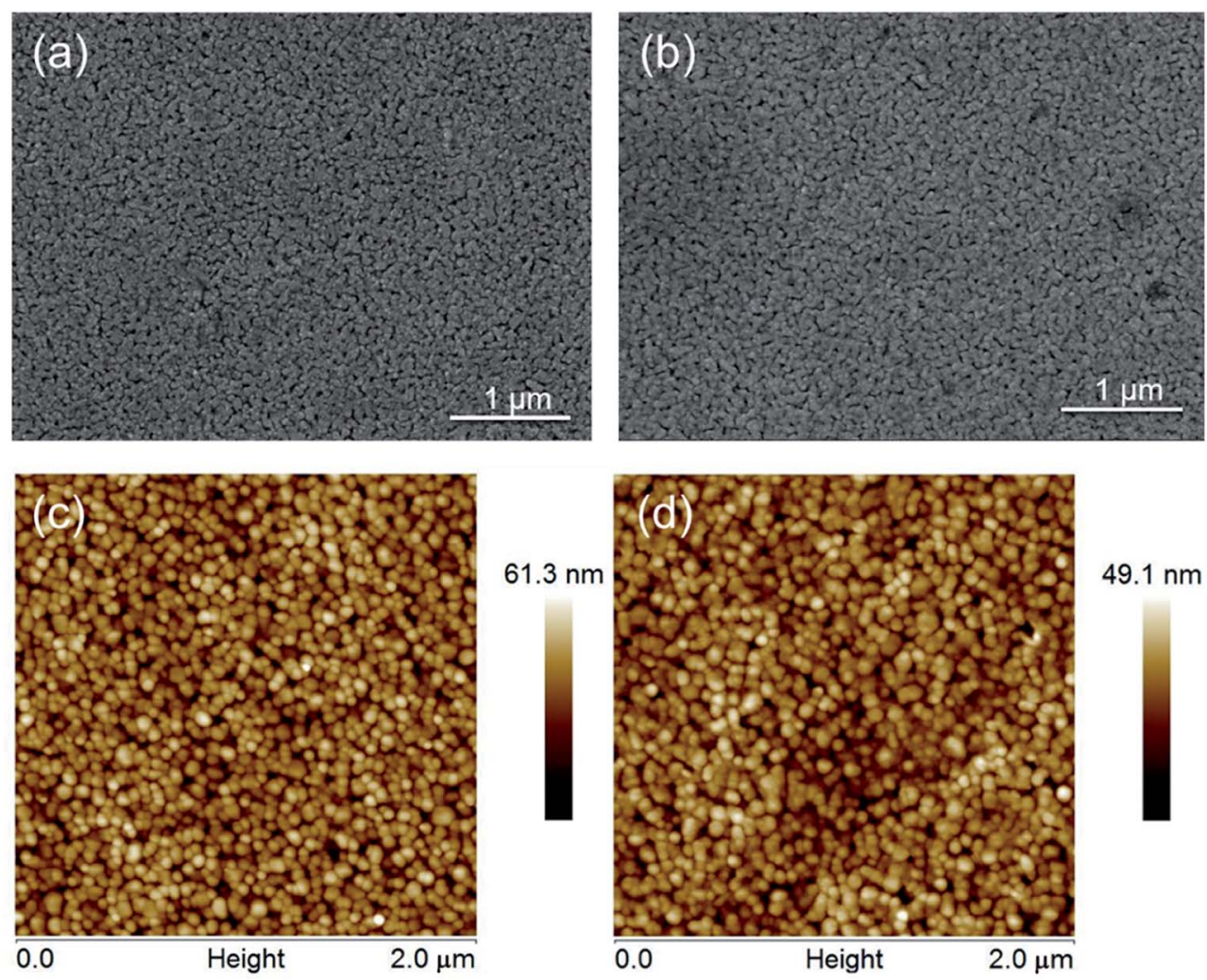

$49.1 \mathrm{~nm}$

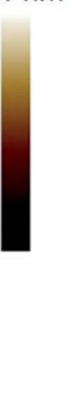

Fig. 1 SEM images of (a) ZnO and (b) ZnO/ZnS nanofilms and AFM images of (c) ZnO and (d) ZnS/ZnS nanofilms. 
and AFM (Fig. 1(a) and (b)). The morphology of the layers does not change significantly after the formation of the $\mathrm{ZnS}$ coating due to the fact that the ZnS layer consists of sphalerite crystals measuring about $3 \mathrm{~nm},{ }^{24}$ and its thickness is in the range of 7 to $10 \mathrm{~nm}$. The ZnS passivation film is formed in hydrogen sulfide $\left(\mathrm{H}_{2} \mathrm{~S}\right)$ in gas phase, which resulted in the film closely following the morphology of the bottom layer. A very thin ZnS film is evenly synthesized on the top of $\mathrm{ZnO}$ layer due to the fact that each $\mathrm{ZnO}$ crystal is surrounded by $\mathrm{H}_{2} \mathrm{~S}$. The $\mathrm{ZnS}$ film does not affect the polycrystalline nature of the $\mathrm{ZnO}$ layer. The high surface area to volume ratio, which is a crucial element for realizing further applications and design nanodevices, remains unchanged.

The roughness of the $\mathrm{ZnO}$ film does not change significantly during the sulfidation process. However, the $\mathrm{ZnO}$ nanolayer was found to have a higher roughness value than $\mathrm{ZnO} / \mathrm{ZnS}$ (Table 1). The roughness decreases after the sulfidation process by the gaps between the crystals in the polycrystalline $\mathrm{ZnO}$ matrix being filled, which becomes slightly smoother (Table 1).

The X-ray diffraction patterns for samples of $\mathrm{ZnO}$ and $\mathrm{ZnO} /$ $\mathrm{ZnS}$ share the characteristic hexagonal wurtzite structure of ZnO (Fig. 2), according to the ICDD database (PDF: 04-0032106). The $\mathrm{ZnO} / \mathrm{ZnS}$ pattern contains an additional peak at 28.9 deg corresponding to the (111) lattice plane of cubic phase of ZnS (ICDS: 01-080-0020); this peak, the most intense in a typical $\mathrm{X}$-ray diffraction pattern for cubic ZnS, indicates the nanocrystalline size nature of the ZnS top film. It has been noted previously for nanocrystalline grain-size $\mathrm{ZnS}$ thin films deposited by chemical bath ${ }^{28}$ and $\mathrm{ZnS}$ nanoparticles. ${ }^{29}$ The results are also consistent with our previous study, ${ }^{24}$ which indicates that the $\mathrm{ZnS}$ coating possesses a ZnS sphalerite structure with a $3 \mathrm{~nm}$ mean diameter of the crystals (Transmission Electron

Table 1 Roughness parameters of $\mathrm{ZnO}$ and $\mathrm{ZnO} / \mathrm{ZnS}$ nanofilms

\begin{tabular}{lll}
\hline & ZnO film & ZnO/ZnS film \\
\hline$R_{\mathrm{q}}$, square roughness (nm) & 6.54 & 5.98 \\
$R_{\mathrm{a}}$, average deviation $(\mathrm{nm})$ & 5.21 & 4.66
\end{tabular}

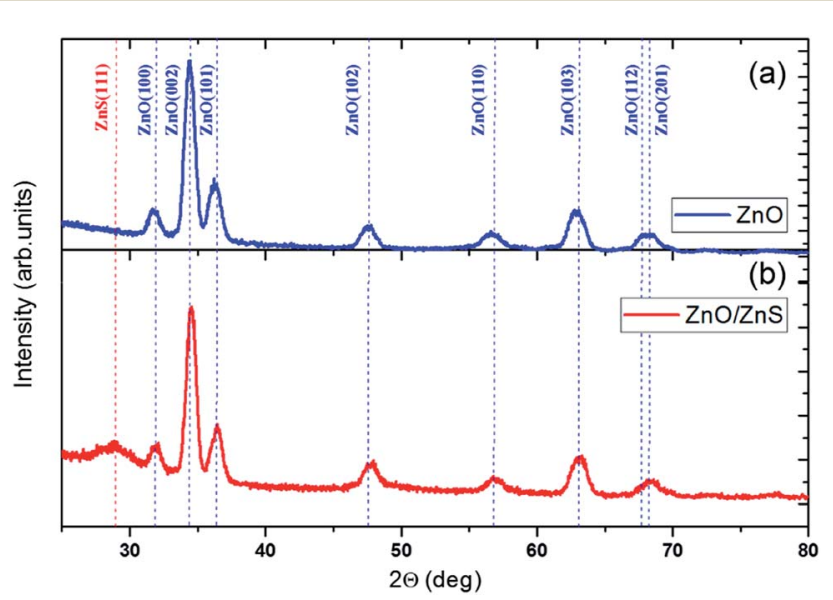

Fig. 2 XRD patterns of (a) $\mathrm{ZnO}$ and (b) ZnO/ZnS nanofilms.
Microscopy, electron diffraction pattern). EDX examination revealed that the films consist of zinc and oxygen before the passivation process, the presence of sulfur was noted only for the $\mathrm{ZnO} / \mathrm{ZnS}$ films.

The infrared spectra of both $\mathrm{ZnO}$ and $\mathrm{ZnO} / \mathrm{ZnS}$ films are presented in Fig. 3. The broad peaks at around $3200 \mathrm{~cm}^{-1}$ and $1000 \mathrm{~cm}^{-1}$ are attributed to $\mathrm{OH}$ and $\mathrm{ZnO}-\mathrm{OH}$ vibration, ${ }^{30}$ respectively. The characteristic $\mathrm{ZnO}$ absorption bands were observed at around $550 \mathrm{~cm}^{-1}$ and $480 \mathrm{~cm}^{-1}$. 31

It was found that the intensity of these bands decreased for $\mathrm{ZnO}$ nanoparticles covered partially with $\mathrm{ZnS}$ in comparison to pure $\mathrm{ZnO}$ nanostructures. ${ }^{30}$ These peaks are not found at the spectra of $\mathrm{ZnO} / \mathrm{ZnS}$ nanolayers, indicating that the $\mathrm{ZnS}$ layer was successfully formed on the surface of $\mathrm{ZnO}$, resulting in the extinguishing of the absorption bands related to $\mathrm{ZnO}$ vibration.

Fig. 4 shows the Raman spectra of $\mathrm{ZnO}$ and $\mathrm{ZnO} / \mathrm{ZnS}$ films at an excitation wavelength of $488 \mathrm{~nm}$ in the 200 to $800 \mathrm{~cm}^{-1}$ spectral range. ZnO film (Fig. 4(a)) is characterized by the fundamental optical modes typical for wurtzite structure with $C_{6 \mathrm{v}}$ point group symmetry. The modes for $\mathrm{ZnO}$ before the sulfidation process are centered at around 332, 380, 411, 437, 582 and $660 \mathrm{~cm}^{-1}$, and are attributed to the processes $\mathrm{E}_{2}(\mathrm{high})-$ $\mathrm{E}_{2}$ (low), $\mathrm{A}_{1}$ (TO), $\mathrm{E}_{1}(\mathrm{TO}), \mathrm{E}_{2}$ (high), $1 \mathrm{LO}$ and TA $+\mathrm{LO}$, respectively. $^{32} 1 \mathrm{LO}$ mode corresponds to the superimposition of $\mathrm{A}_{1}(\mathrm{LO})$ and $\mathrm{E}_{1}(\mathrm{LO})$, which are characteristic of the presence of randomly-oriented $\mathrm{ZnO}$ crystals on the substrate. ${ }^{33}$ The strong peak at $437 \mathrm{~cm}^{-1}$ is associated with the high-frequency $\mathrm{E}_{2}$ mode of oxygen atoms and indicates a $\mathrm{ZnO}$ wurtzite hexagonal phase. The Raman spectrum of $\mathrm{ZnO} / \mathrm{ZnS}$ nanofilm (Fig. 4(b)) reveals all the above mentioned modes characteristic of pure $\mathrm{ZnO}$ and additional modes related to the presence of a $\mathrm{ZnS}$ top layer. A large number of peaks are present in the range 200 to $350 \mathrm{~cm}^{-1}$ attributed to $\mathrm{ZnS}$, including two modes of the first-order Raman frequencies characteristic of zinc blende, indicated in Fig. 4(b) as ${ }^{*}, \mathrm{~T}_{2}(\mathrm{TO})$ at $279 \mathrm{~cm}^{-1}$ and $\mathrm{T}_{2}(\mathrm{LO})$ at $350 \mathrm{~cm}^{-1} \cdot{ }^{34}$ The peaks at about 220 and $260 \mathrm{~cm}^{-1}$ are attributed to second-order Raman scattering. ${ }^{35}$ Moreover, the $\mathrm{ZnO} \mathrm{E}_{2}$ mode is slightly shifted at $436 \mathrm{~cm}^{-1}$, indicating no significant tensile stress between the

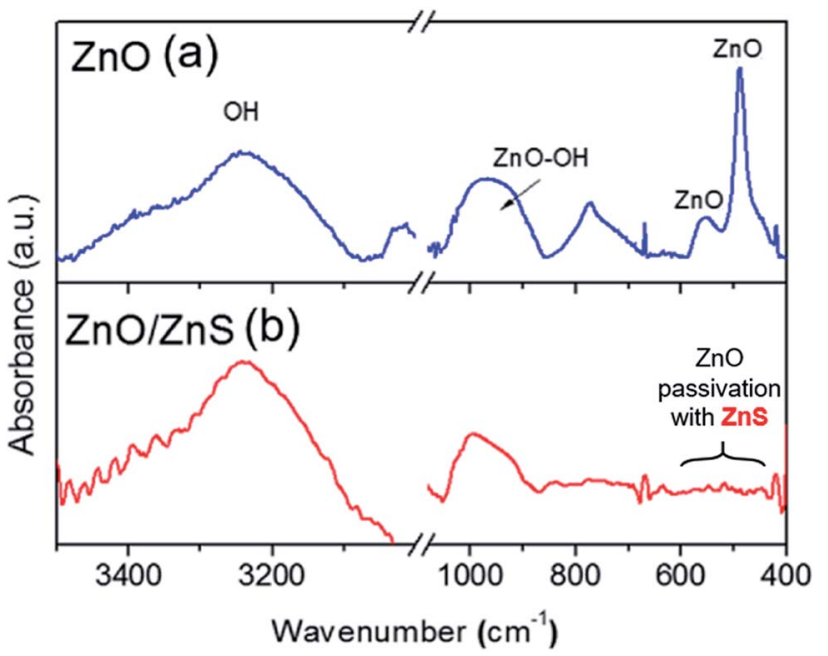

Fig. 3 Infrared spectra of (a) $\mathrm{ZnO}$ and (b) $\mathrm{ZnO} / \mathrm{ZnS}$ nanofilms. 


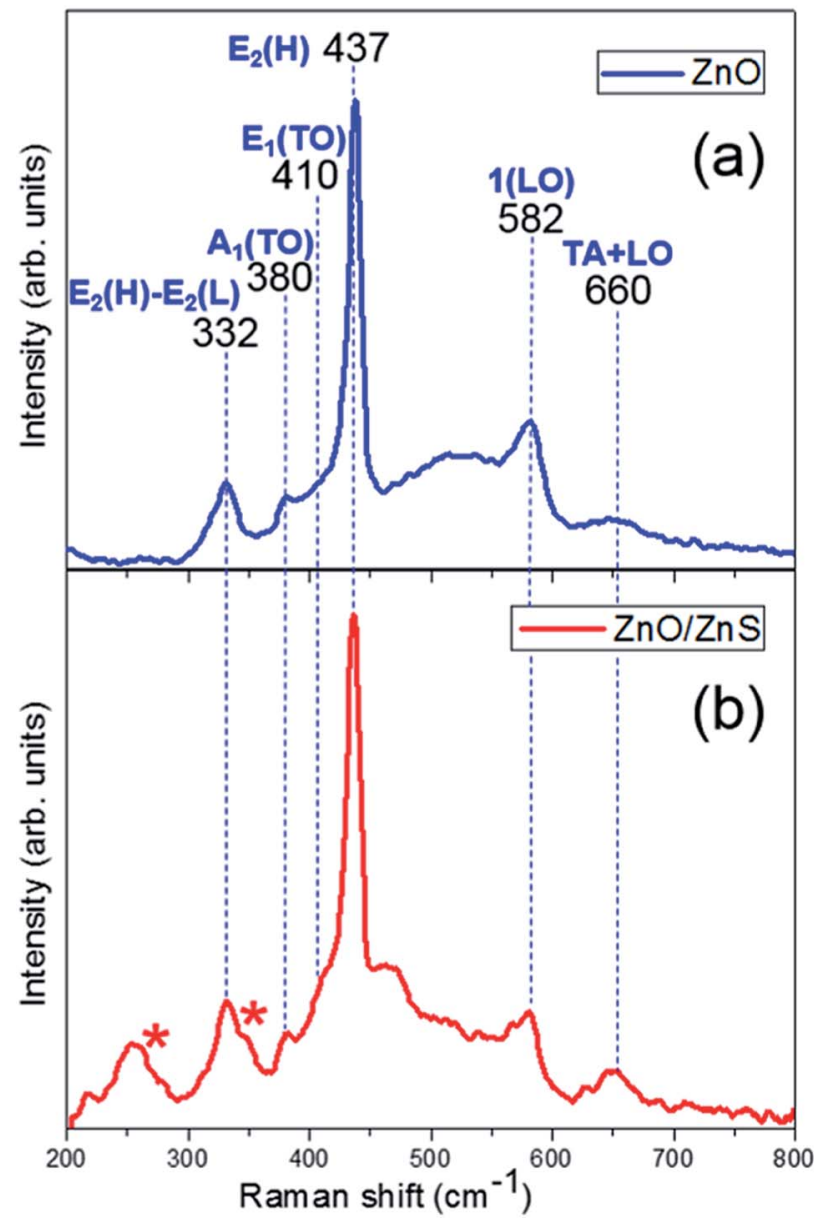

Fig. 4 Raman spectra of (a) $\mathrm{ZnO}$ and (b) $\mathrm{ZnO} / \mathrm{ZnS}$ nanofilms.

top sphalerite $\mathrm{ZnS}$ and bottom wurtzite $\mathrm{ZnO}$ layers. The vibrational modes for $\mathrm{ZnO}$ and $\mathrm{ZnS}$ observed simultaneously for films after the sulfidation process confirm the formation of $\mathrm{ZnO} / \mathrm{ZnS}$ heterostructures.

To study the mechanical properties of the films before and after the passivation process, the values of the elastic modulus and hardness were determined using nanoindentation techniques. The Young's modulus values were estimated to be 72.40 and $82.36 \mathrm{GPa}$ for ZnO film before and after the sulfidation process, respectively (Fig. 5(a)). The hardness scores of the sample before and after passivation were also measured, these were calculated as $1.1 \mathrm{GPa}$ for $\mathrm{ZnO}$ alone and $1.8 \mathrm{GPa}$ for the $\mathrm{ZnO} / \mathrm{ZnS}$ nanolayer (Fig. 5(b)). The elastic modulus and hardness of the samples increased by $14 \%$ and $64 \%$ after $\mathrm{ZnS}$ coating, respectively. The nanoindentation tests for $\mathrm{ZnO}$ films deposited by a radio frequency magnetron sputtering system found Young's modulus to range from 68 to $125 \mathrm{GPa}$, similar to our results. ${ }^{36}$ However, the hardness was slightly higher for $\mathrm{ZnO}$ sputtered films, probably due to the differences in the route of synthesis, film morphology and shape of the crystal: i.e. conelike rather than bead-like. It had also been found previously that crystal size influences the mechanical properties of $\mathrm{ZnO}$ materials. The hardness of $a$-plane $\mathrm{ZnO}$ thin films grew from 8.6 to $11.3 \mathrm{GPa}$ as a result of increasing the grain size from 52 to $84 \mathrm{~nm}^{37}$

Our results indicate that the addition of the thin $\mathrm{ZnS}$ top layer significantly improved the mechanical properties of the ZnO film and makes it more resistant to deformation. The thin ZnS layer enhances ZnO hardness and elastic modulus due to improving quality of $\mathrm{ZnO}$ surface. ${ }^{38,39}$ The passivation process of $\mathrm{ZnO}$ remove surface defects and significantly improved its mechanical properties, for example, elastic moduli in case of $\mathrm{ZnO}$ nanowires. ${ }^{38}$ The previous optical studies of the $\mathrm{ZnO} / \mathrm{ZnS}$ nanofilms showed that sulfidation process removed $\mathrm{ZnO}$ surface defects. ${ }^{24}$ The cathodoluminescence (CL) intensity of the band-to-band emission for $\mathrm{ZnO} / \mathrm{ZnS}$ nanolayer was one order of magnitude higher than that of ZnO. The emission mechanisms for $\mathrm{ZnO}$ nanolayers were enhanced, and their surface defects effectively passivated, by the ZnS film. ${ }^{40}$ The surface defects, sources of non-radiative recombination were removed by the $\mathrm{ZnS}$ coating formation. The crystal size is also a key factor influence mechanical properties. The hardness of ZnS nanobelts increased by $79 \%$ in comparison to bulk material and the nanostructures exhibited significant creep under
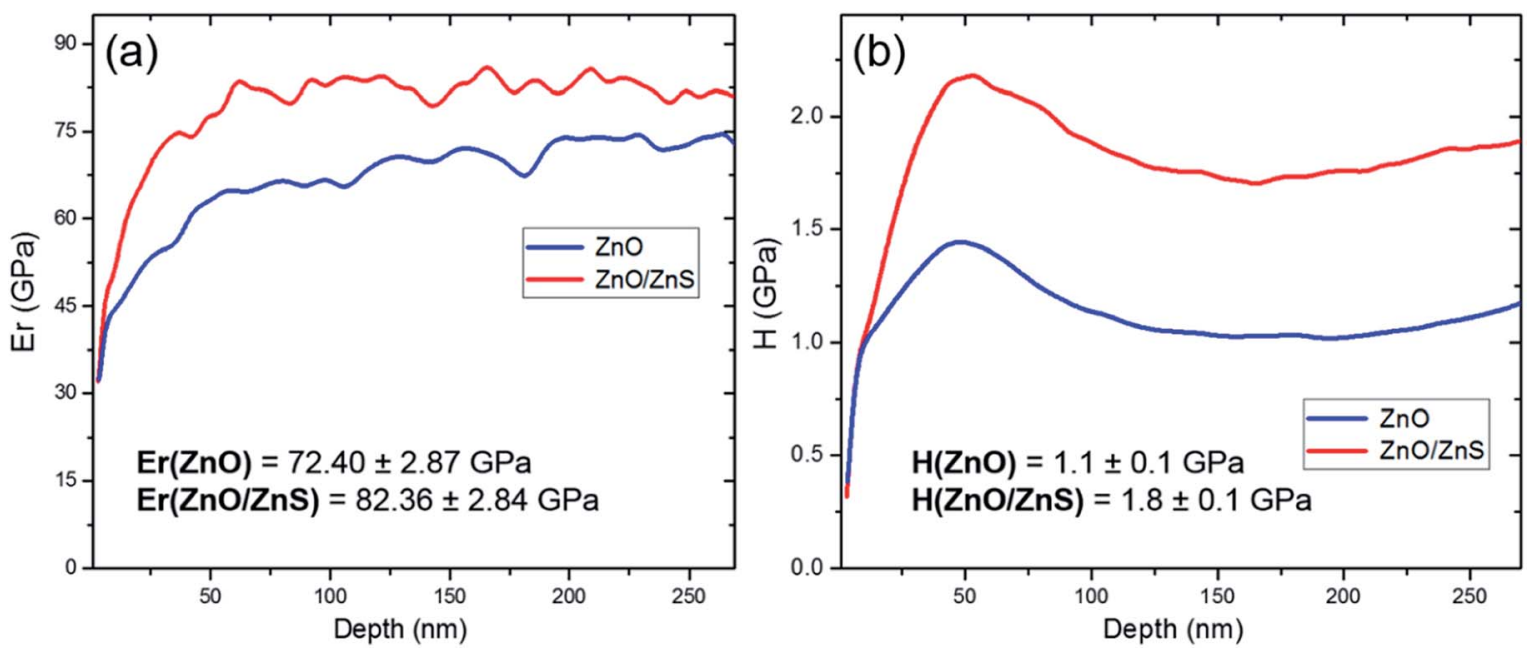

Fig. 5 The evaluation of (a) Young's modulus and (b) hardness according to sample depth of ZnO and ZnO/ZnS nanofilms. 

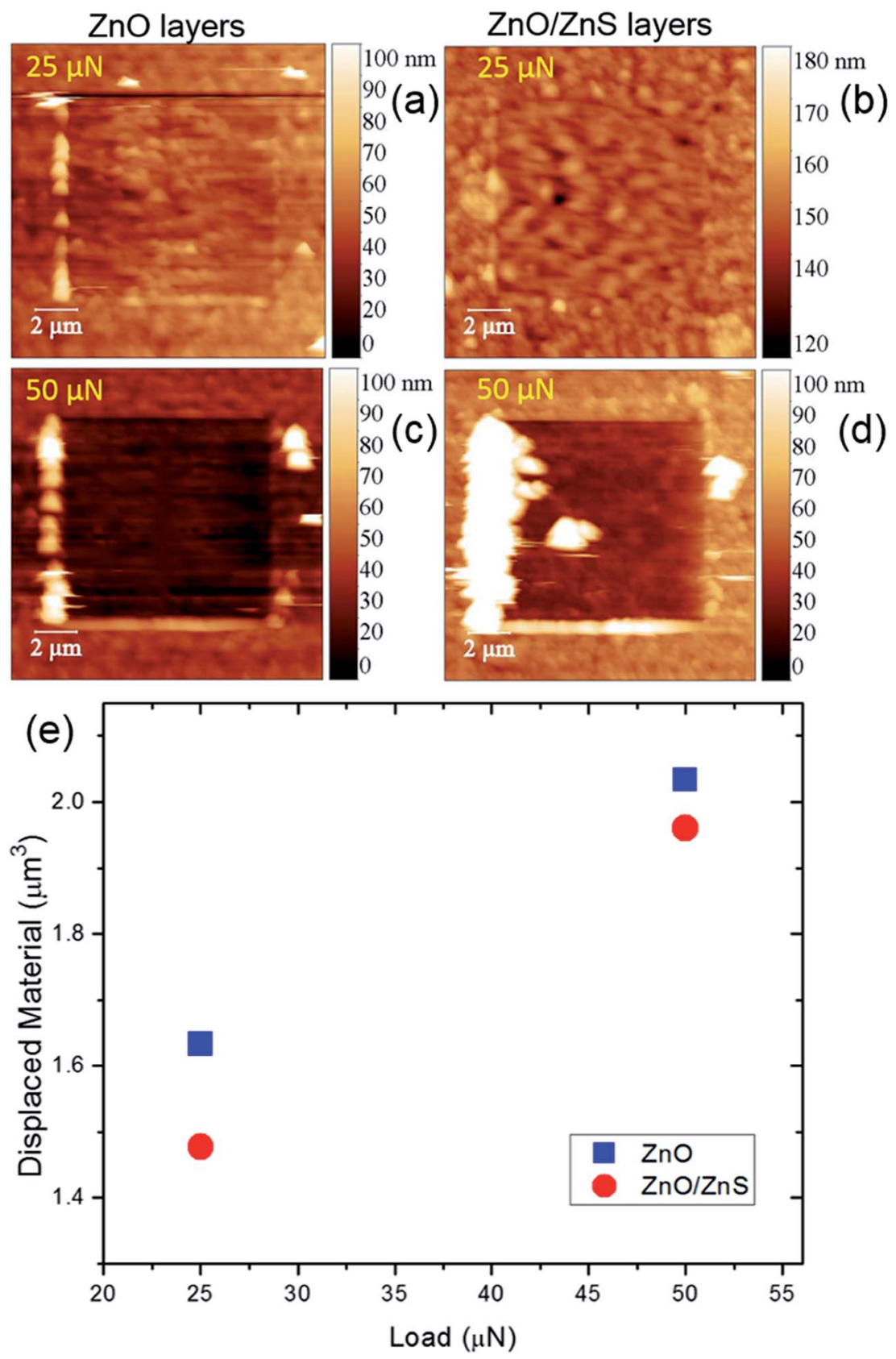

Fig. 6 (a and c) ZnO and (b and d) ZnO/ZnS nanofilms after a nanowear test performed by holding a constant force of (a and b) 25 and (c and d) $50 \mu \mathrm{N}$ and (e) the values of the displaced material calculated by the residual imprint.

a constant load indentation at room temperature. ${ }^{41}$ In our system, ZnS top layer consists of crystals with a diameter of $3 \mathrm{~nm}$ and enhances the hardness of $\mathrm{ZnO}$ film by $64 \%$.

To confirm the higher mechanical stability of the film after ZnS coating, a nanowear test was performed by holding two different constant forces of 25 and $50 \mu \mathrm{N}$. The value of displaced material, calculated by the residual imprint, was estimated to be about 1.633 and $2.033 \mu \mathrm{m}^{3}$ for 25 and $50 \mu \mathrm{N}$ of applied force for $\mathrm{ZnO}$ films, respectively (Fig. 6). These values changed to 1.477 and $1.960 \mu \mathrm{m}^{3}$ after the sulfidation process for films treated with 25 and $50 \mu \mathrm{N}$ forces, respectively. Lower dislocate and damage material values were noted for $\mathrm{ZnO} / \mathrm{ZnS}$ film at both applied forces, which suggests that the results are consistent with our nanomechanical tests.
The addition of a $\mathrm{ZnS}$ coating also influences the electrical properties of the $\mathrm{ZnO}$ nanofilms, which were investigated before and after the sulfidation process (Table 2 ). The conductivity of the $\mathrm{ZnO}$ film increases about 500-fold after $\mathrm{ZnS}$ coating. The $\mathrm{ZnO} / \mathrm{ZnS}$ nanofilms are significantly more conductive because the passivation process removes surface defects and

Table 2 The conductivity value of $\mathrm{ZnO}$ and $\mathrm{ZnO} / \mathrm{ZnS}$ nanofilms synthesized on $\mathrm{Si} / \mathrm{SiO}_{2}$ substrates

\begin{tabular}{lll}
\hline & ZnO film & ZnO/ZnS film \\
\hline Conductivity $\sigma(1 / \Omega \mathrm{m})$ at $21^{\circ} \mathrm{C}$ & 0.0039 & 1.8573
\end{tabular}


environmental influences. The thin $\mathrm{ZnS}$ layer releases oxygen molecules $\left(\mathrm{O}_{2}\right)$ from $\mathrm{ZnO}$ surface, which can trap free carriers from the nanostructures. As a result of $\mathrm{O}_{2}$ and free-electron complex formation, the carrier density decreases at the surface of n-type $\mathrm{ZnO}$, which is accompanied by greater depletion region. After passivation, $\mathrm{ZnO}$ is unable to react with gases, the trapped electrons are released and the conductivity increases. The mechanism has been described in detail for various 1D $\mathrm{ZnO}$ nanostructures such as nanowires ${ }^{42}$ and nanofibers, ${ }^{43}$ and for $2 \mathrm{D}$ structures such as nanowalls. ${ }^{44}$ The process has been proposed for use in various gas detectors, the sensitivity and selectivity of which depend on the ability for $\mathrm{O}_{2}$ to be removed from the semiconductor surface.

Fig. 7 shows the maps of electrical signal of $\mathrm{ZnO}$ and $\mathrm{ZnO} / \mathrm{ZnS}$ nanofilms obtained by the C-AFM technique. The topography of the selected layer parts for C-AFM measurements was visualized by AFM in contact mode. The images were obtained for a large area of $5 \mu \mathrm{m} \times 5 \mu \mathrm{m}$ to check the continuity of the electrical signal and breakdown presence. C-AFM maps for both films are characterized by a uniform signal and the layers do not have any region with higher or lower conductivity. Moreover, C-AFM maps do not contain the grain boundaries clearly visible on the layer topography images. The same result has been obtained for different scanning areas and samples. The voltage output of $\mathrm{ZnO}$ and $\mathrm{ZnO} / \mathrm{ZnS}$ nanolayers is uniformly distributed across the whole surface, despite the polycrystalline nature of the films.
To study the stability of the samples in liquids, $\mathrm{ZnO}$ and $\mathrm{ZnO} / \mathrm{ZnS}$ nanofilms were immersed in DI water. The experiment was carried out under ambient conditions and the nanofilms were not treated with any additional factors. After seven days, the $\mathrm{ZnO}$ nanolayer dissolved, while the $\mathrm{ZnO} / \mathrm{ZnS}$ nanolayer remained stable and water-insoluble (Fig. 8). Residues of the crystals remained in some regions of the ZnO samples, which were not completely dissolved (Fig. 8(b)). ZnO-based materials are low stable in water, especially nanostructures due to their high surface area to volume ratio and a large number of surface defects in comparison to the bulk structures. ${ }^{45}$ The dissolution rate of $\mathrm{ZnO}$ nanomaterials in water depends on crystal size. The smaller $\mathrm{ZnO}$ grains dissolve in water much more quickly: $\mathrm{ZnO}$ nanofibers calcined at $700{ }^{\circ} \mathrm{C}$ remain water-stable much longer than nanofibers obtained at $500{ }^{\circ} \mathrm{C}$ due to the fact that crystal size was larger for nanostructures heated at a higher temperature. ${ }^{46}$ The mean diameter of $\mathrm{ZnO}$ crystals calcined at $500{ }^{\circ} \mathrm{C}$ was calculated previously based on SEM micrographs and it was estimated to be about $37 \mathrm{~nm}$, but the size of some particles in the sample reached $60 \mathrm{~nm} .{ }^{24}$ Most probably, either the experiment was too short for the dissolution of large crystals, or was sufficient to break the continuity of the layer but the liquid was not able to penetrate the closely-connected $\mathrm{ZnO}$ beads. ZnO nanostructures are usually dissolved in the hydrophilic fluids for a few hours and degraded into different ions, such as $\mathrm{Zn}_{2}{ }^{+}$, $\mathrm{ZnO}_{2}{ }^{2-}$ and $\mathrm{Zn}\left(\mathrm{NH}_{3}\right)_{4}{ }^{2+}$ depending on the etching agent. ${ }^{47}$ The
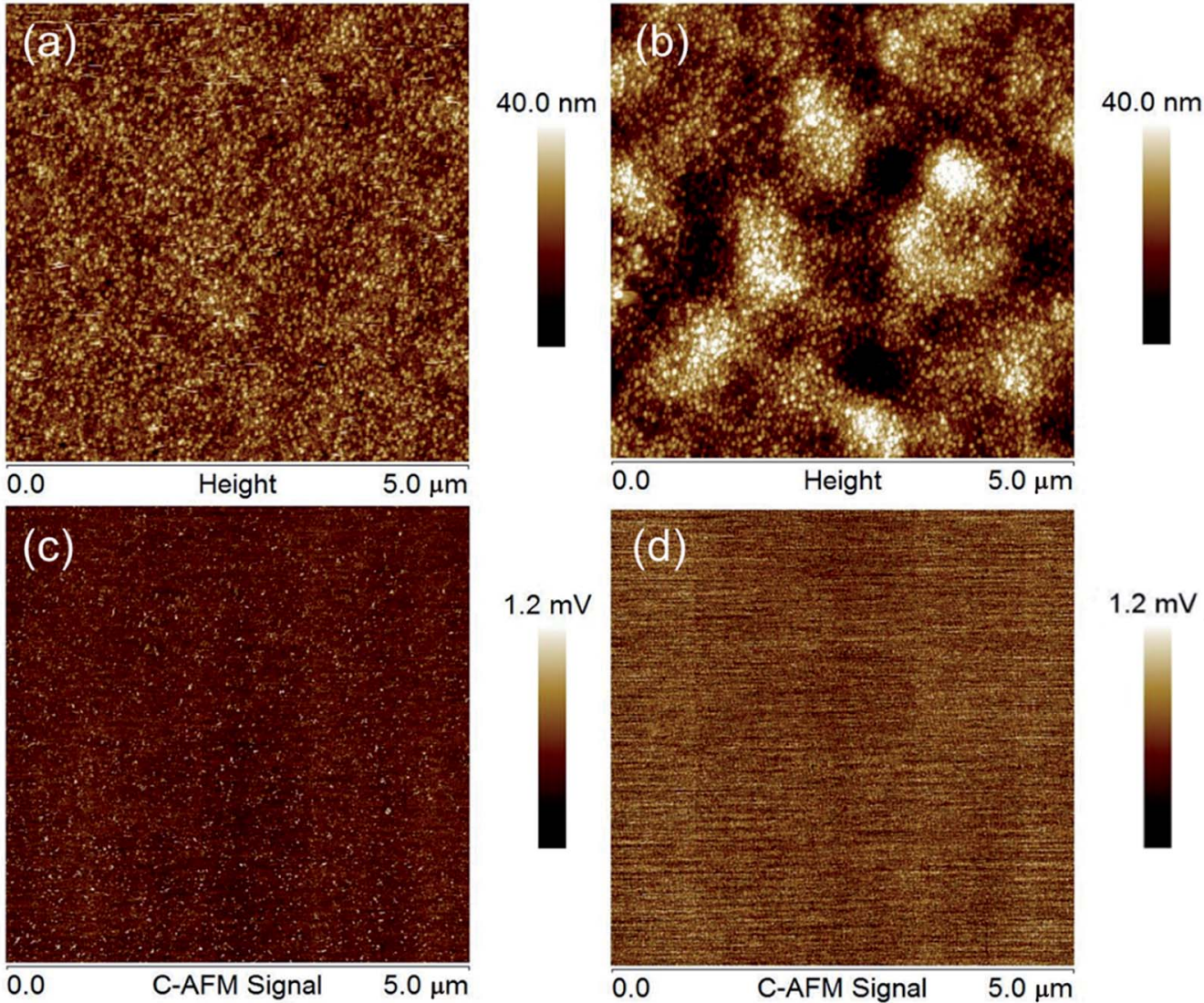

$1.2 \mathrm{mV}$

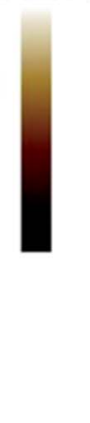

Fig. 7 AFM images of (a) ZnO and (b) ZnO/ZnS nanofilms measured in contact mode. C-AFM images of (c) ZnO and (d) ZnO/ZnS nanofilms. Dimensions of the images: $5 \mu \mathrm{m} \times 5 \mu \mathrm{m}$. The topography and C-AFM signal were obtained for the same sample area. 

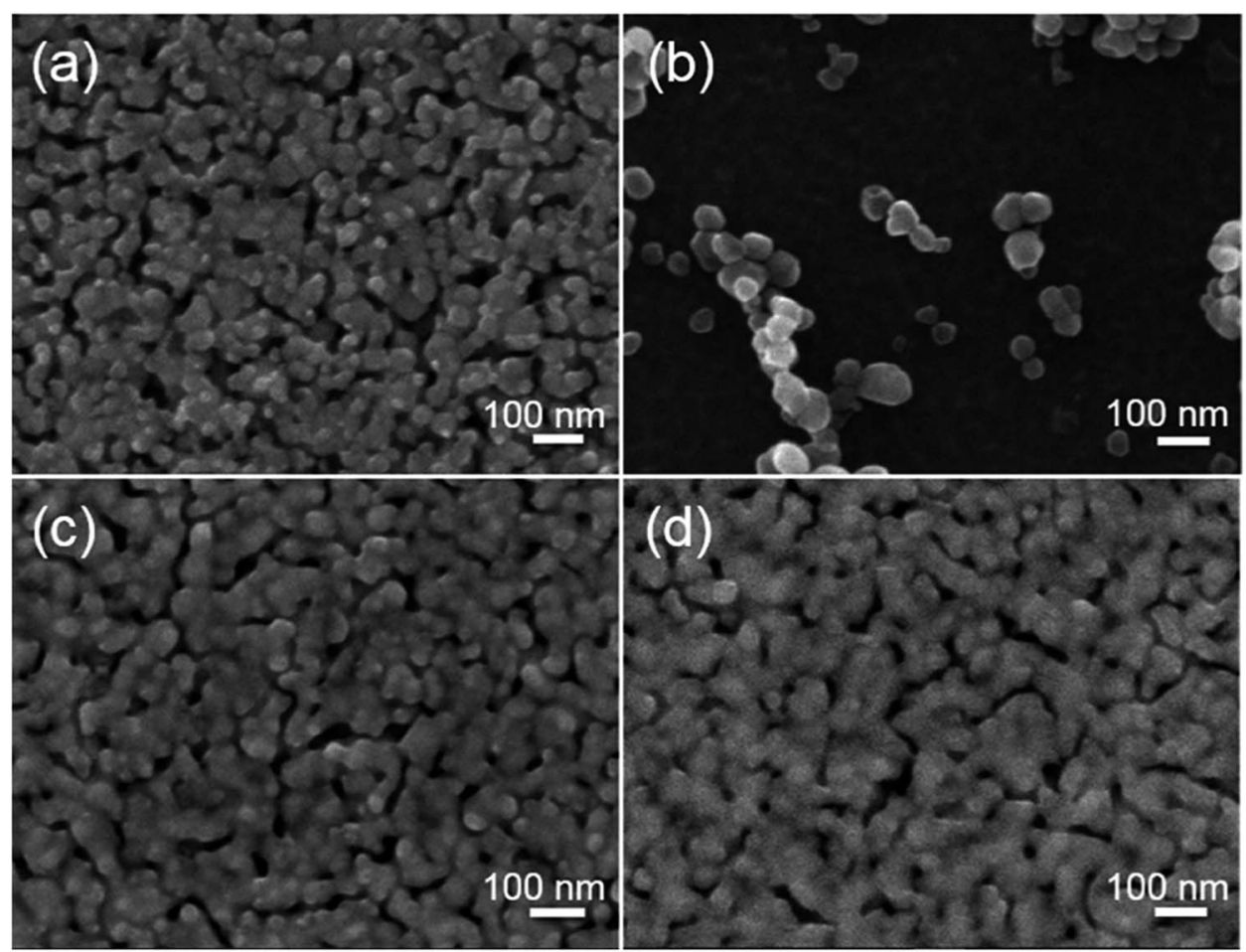

Fig. 8 SEM images of ( $a$ and $b$ ) $\mathrm{ZnO}$ and ( $c$ and $d$ ) $\mathrm{ZnO} / \mathrm{ZnS}$ nanofilms ( $a$ and $c$ ) untreated with water and (b and d) immersed in DI water for seven days.

dissolution process is caused mainly due to $\mathrm{ZnO}$ surface polarity. ${ }^{48} \mathrm{ZnO}$ nanocrystals are characterized by two sublattices consisting of corner-sharing tetrahedra with $\mathrm{Zn}_{2}{ }^{+}$and $\mathrm{O}_{2}{ }^{-}$ions. It results in forming two faces, positively charged with zinc ions (0001) and negatively charged with oxygen ions (000-1). That arrangement allows interacting $\mathrm{ZnO}$ with both positive and negative charges. ${ }^{45} \mathrm{ZnS}$ significantly decreases a surface charge and for example partially sulfidized $\mathrm{ZnO}$ nanoparticles decrease the rate of the dissolution process. ${ }^{49}$ In our system, ZnS thin layer completely covers $\mathrm{ZnO}$ surface and inhibits interaction with ions from the solution. It results in insolubility $\mathrm{ZnO} / \mathrm{ZnS}$ films in a hydrophilic environment.

Our findings indicate that $\mathrm{ZnS}$ surface passivation in a gas phase of hydrogen sulfide is an effective way of protecting $\mathrm{ZnO}$ nanostructures against dissolution in a water-based environment. The protection of $\mathrm{ZnO}$ surfaces against environmental conditions, oxygen chemisorption and natural growth of $\mathrm{ZnCO}_{3}$ nanostructures is a crucial issue for the design of effective devices. ${ }^{50,51} \mathrm{ZnS}$ is a common choice as a semiconductor for coating $\mathrm{ZnO}$ cores due to its high chemical stability at different $\mathrm{pH}$ values and its low toxicity. ${ }^{12}$ Additionally, the passivation process carried out in a gas phase allowed the polycrystalline structure of the base ZnO layer to be preserved, which did not change significantly. The active area, characterized by a high surface area to volume ratio, did not decrease after covering with $\mathrm{ZnS}$. $\mathrm{ZnO} / \mathrm{ZnS}$ nanofilms can be applied for different devices requiring a high surface area, such as sensors and biosensors, and the need to operate in different environments.

The antimicrobial properties of $\mathrm{ZnO}$ and $\mathrm{ZnO} / \mathrm{ZnS}$ nanofilms were investigated against Gram-negative bacteria of $E$. coli.
Fig. 9(a-c) shows the agar plates with bacterial colonies recultivated after deposition on $\mathrm{ZnO}$ and $\mathrm{ZnO} / \mathrm{ZnS}$ nanolayers, and on a pure substrate as a control sample. Both nanolayer samples presented significantly fewer colonies, demonstrating their antimicrobial potential. A quantitative analysis of the bacterial survival rates was obtained by the colony forming unit count method. Fig. 9(d) presents the values of $E$. coli viability as below $40 \%$ and $30 \%$ for $\mathrm{ZnO}$ and $\mathrm{ZnO} / \mathrm{ZnS}$ nanofilms, respectively, indicating that the $\mathrm{ZnS}$ coating does not have a negative influence on $\mathrm{ZnO}$ antibacterial properties and even slightly enhances them.

The antibacterial properties of $\mathrm{ZnO}$ are well known and are commonly applied for a range of treatments. ZnO materials enable the production of reactive oxygen species (ROS) such as peroxide $\left(\mathrm{O}_{2}{ }^{-2}\right)$, hydroxyl radicals $\left(\mathrm{OH}^{-}\right)$and hydrogen peroxide $\left(\mathrm{H}_{2} \mathrm{O}_{2}\right)$, which can inhibit bacterial growth. ${ }^{52}$ The other mechanism concerns the release and adhesion of $\mathrm{Zn}^{2+}$ ions from $\mathrm{ZnO}$ structures, resulting in mechanical damage to the cell wall. ${ }^{53}$ Additionally, the antimicrobial activity of ZnO may well be enhanced for nano-size materials due to their high surface area to volume ratio. In case of our films, their polycrystalline nature can also increase the $\mathrm{ZnO}$-specific area and improve the antimicrobial reactivity.

The viability of the $E$. coli cells was found to slightly decrease after the sulfidation process, (Fig. 9(d)), which may be associated with the size of the $\mathrm{ZnS}$ crystals. In our previous study, the mean diameter of the crystal was estimated to be about $3 \mathrm{~nm} .{ }^{24}$ The small size of the $\mathrm{ZnS}$ beads and the electrostatic interaction between the positively-charged $\mathrm{ZnS}$ crystals and the negativelycharged cell membrane resulted in easier interaction with 

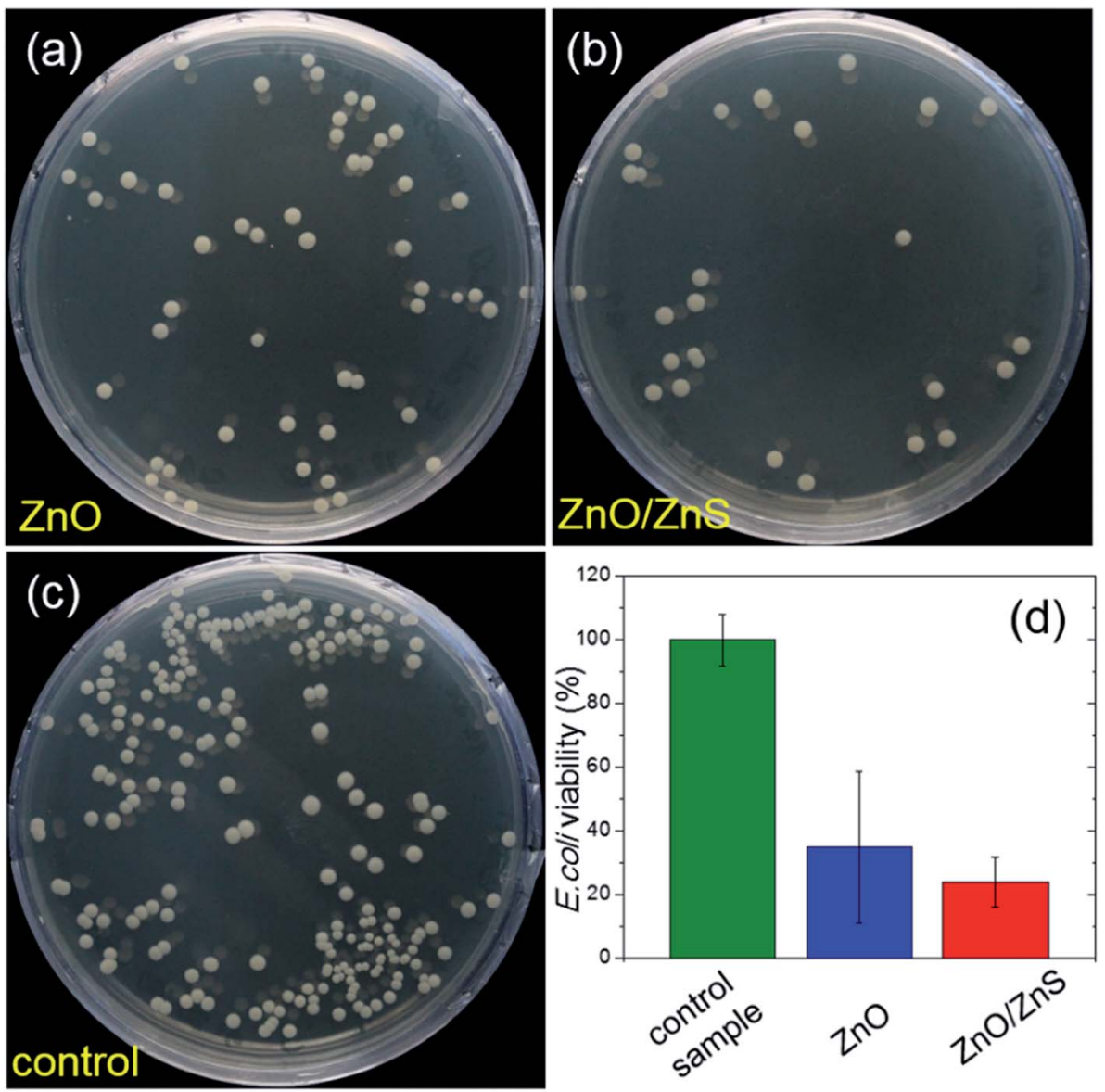

Fig. 9 Antibacterial activity of (a) $\mathrm{ZnO}$ and (b) $\mathrm{ZnO} / \mathrm{ZnS}$ nanofilms against $E$. coli. Images of agar plates with $E$. coli bacterial cells recultivated after deposition onto (a) ZnO and (b) ZnO/ZnS nanofilms, and (c) pure substrate as a control sample for four hours. (d) The percentage viability of E. coli recultivated after deposition onto $\mathrm{ZnO}, \mathrm{ZnO} / \mathrm{ZnS}$ nanofilms and control sample. Survival rates were obtained by the colony forming unit count method.

bacteria and thus enhanced antibacterial effects against $E$. coli. ${ }^{54}$ Moreover, the ZnS surface layer can interact with thiol groups of the bacterial cell membrane protein and deactivate them, resulting in decreased permeability and leading to cell death..$^{55}$

\section{Conclusion}

The study demonstrates that mechanical and electrical properties of $\mathrm{ZnO}$ polycrystalline nanofilms are enhanced after $\mathrm{ZnS}$ surface passivation. A coating of a $\mathrm{ZnS}$ thin layer was synthesized in a gas-phase sulfidation process, resulting in $\mathrm{ZnO} / \mathrm{ZnS}$ film formation. The presence of $\mathrm{ZnS}$ was confirmed by infrared and Raman spectroscopy analysis. XRD patterns indicate that the $\mathrm{ZnO}$ parts have a wurtzite structure and suggest the creation of nanocrystalline ZnS. The Young's modulus and nanohardness were found to be about $14 \%$ and $64 \%$ greater following ZnS layer formation, and indicate lower susceptibility to damage. Nanowear tests carried out using nanoindentation methods and different applied forces found the dislocation and damage of materials to be lower with the ZnS-coated layer. Furthermore, the electrical conductivity of the $\mathrm{ZnO}$ nanofilms increased about 500-fold after $\mathrm{ZnS}$ formation as a result of surface defect passivation and the removal of oxygen molecules, which become incapable of reacting with free carriers. C-AFM maps found the top layer to be of high quality and free of defects, and the surface active area does not change significantly due to the fact that it forms in the presence of hydrogen sulphide and follows the morphology of the ZnO bottom film. The ZnS coating also enhances the stability of ZnO films in a biological environment. The $\mathrm{ZnO} / \mathrm{ZnS}$ films were found to be insoluble in water for over seven days, while $\mathrm{ZnO}$ nanolayers dissolve. Additionally, $\mathrm{ZnO}$ antimicrobial properties against $E$. coli slightly increased after ZnS passivation. Our findings indicate that $\mathrm{ZnO}$ surface passivation is required for designing future devices to improve its stability in different environments and to enhance its mechanical, electrical and antibacterial properties.

\section{Conflicts of interest}

There are no conflicts to declare.

\section{Acknowledgements}

The research was supported by Polish Ministry of Science and Higher Education (Grant "Iuventus Plus" No. 0018/IP2/2015/73, 2015-2017) and Nation Centre for Research and Development 
(PBS1/A9/13/2012). The authors thank Dr Zuzanna Pietralik (Department of Macromolecular Physics, Adam Mickiewicz University) for assistance during FTIR measurements.

\section{References}

1 M. Singh, K. Manoli, A. Tiwari, T. Ligonzo, C. Di Franco, N. Cioffi, G. Palazzo, G. Scamarcio and L. Torsi, J. Mater. Chem. C, 2017, 5, 3509-3518.

2 H. Singh, A. Kumar, B. S. Bansod, T. Singh, A. Thakur, T. Singh and J. Sharma, RSC Adv., 2018, 8, 3839-3845.

3 Y. C. Chang, J. Alloys Compd., 2016, 664, 538-546. 4 Y.-C. Liang and C.-C. Wang, RSC Adv., 2018, 8, 5063-5070.

5 A. Sadollahkhani, I. Kazeminezhad, J. Lu, O. Nur, L. Hultman and M. Willander, RSC Adv., 2014, 4, 3694036950.

6 D. Chen, F. Huang, G. Ren, D. Li, M. Zheng, Y. Wang and Z. Lin, Nanoscale, 2010, 2, 2062-2064.

7 W. Tian, C. Zhang, T. Zhai, S. L. Li, X. Wang, J. Liu, X. Jie, D. Liu, M. Liao, Y. Koide, D. Golberg and Y. Bando, Adv. Mater., 2014, 26, 3088-3093.

8 X. Gu, S. Zhang, Y. Zhao and Y. Qiang, Vacuum, 2015, 122, 611.

9 E. M. Flores, C. W. Raubach, R. Gouvea, E. Longo, S. Cava and M. L. Moreira, Mater. Chem. Phys., 2016, 173, 347-354.

10 G. Cao, H. Yang, K. Hong, W. Hu and M. Xu, Mater. Lett., 2015, 161, 278-281.

11 A. Brayek, S. Chaguetmi, M. Ghoul, I. Ben Assaker, A. Souissi, L. Mouton, P. Beaunier, S. Nowak, F. Mammeri, R. Chtourou and S. Ammar, RSC Adv., 2016, 6, 30919-30927.

12 A. Baranowska-Korczyc, K. Sobczak, P. Dłuzewski, A. Reszka, B. J. Kowalski, Ł. Kłopotowski, D. Elbaum and K. Fronc, Phys. Chem. Chem. Phys., 2015, 17, 24029-24037.

13 R. Zhang, B. Wang, H. Zhang and L. Wei, Appl. Surf. Sci., 2005, 241, 435-441.

14 S. Tarish, Z. Wang, A. Al-Haddad, C. Wang, A. Ispas, H. Romanus, P. Schaaf and Y. Lei, J. Phys. Chem. C, 2015, 119, 1575-1582.

15 H. Zhao, Y. Dong, P. Jiang, X. Wu, R. Wu and Y. Chen, RSC Adv., 2015, 5, 6494-6500.

16 D. Bao, P. Gao, X. Zhu, S. Sun, Y. Wang, X. Li, Y. Chen, H. Zhou, Y. Wang and P. Yang, Chem.-Eur. J., 2015, 21, 12728-12734.

17 S. Zhang, B. Yin, H. Jiang, F. Qu, A. Umar and X. Wu, Dalton Trans., 2014, 44, 2409-2415.

18 S. C. Rai, K. Wang, Y. Ding, J. K. Marmon, M. Bhatt, Y. Zhang, W. Zhou and Z. L. Wang, ACS Nano, 2015, 9, 6419-6427.

19 Z. Zhao, C. Jiang, X. Pu, C. Du, L. Li, B. Ma and W. Hu, Appl. Phys. Lett., 2016, 108, 153104.

20 B. Ji, J. Zhang, C. Zhang, N. Li, T. Zhao, F. Chen, L. Hu, S. Zhang and Z. Wang, ACS Appl. Nano Mater., 2018, 1, 793-799.

21 A. K. Giri, C. Charan, A. Saha, V. K. Shahi and A. B. Panda, J. Mater. Chem. A, 2014, 2, 16997-17004.
22 A. Baranowska-Korczyc, K. Fronc and D. Elbaum, Method for preparing metal oxide layers, Polish Patent Office, Patent No. PL401419-A1, PL220304-B1, 2014.

23 A. Baranowska-Korczyc, K. Fronc and D. Elbaum, Passivation method of ZnO nanostructures, Polish Patent Office, Patent No. PL220716-B1, 2014.

24 A. Baranowska-Korczyc, A. Reszka, K. Sobczak, T. Wojciechowski and K. Fronc, J. Alloys Compd., 2017, 695, 1196-1204.

25 W. C. Oliver and D. M. Pharr, J. Mater. Res., 1992, 7, 15641583.

26 J. Fu, J. Ji, W. Yuan and J. Shen, Biomaterials, 2005, 26, 66846692.

27 S. Karamdoust, B. Yu, C. V. Bonduelle, Y. Liu, G. Davidson, G. Stojcevic, J. Yang, W. M. Lau and E. R. Gillies, J. Mater. Chem., 2012, 22, 4881.

28 S. S. Kawar and B. H. Pawar, J. Mater. Sci.: Mater. Electron., 2010, 21, 906-909.

29 A. K. Thottoli, A. Kaliani and A. Unni, J. Nanostruct. Chem., 2013, 3, 1.

30 R. Zamiri, D. M. Tobaldi, H. A. Ahangar, A. Rebelo, M. P. Seabra, M. S. Belsley and J. M. F. Ferreira, RSC Adv., 2014, 4, 35383-35389.

31 G. Socrates, Infrared and Raman characteristic group frequencies: Tables and Charts, Wiley, New York, 3rd edn, 2001.

32 Ü. Özgür, Y. I. Alivov, C. Liu, A. Teke, M. A. Reshchikov, S. Doğan, V. Avrutin, S. J. Cho and H. Morkọ, J. Appl. Phys., 2005, 98, 1-103.

33 T. L. Phan, R. Vincent, D. Cherns, N. X. Nghia and V. V Ursaki, Nanotechnology, 2008, 19, 475702.

34 Y. C. Cheng, C. Q. Jin, F. Gao, X. L. Wu, W. Zhong, S. H. Li and P. K. Chu, J. Appl. Phys., 2009, 106, 123505.

35 A. G. Milekhin, N. A. Yeryukov, L. L. Sveshnikova, T. A. Duda, C. Himcinschi, E. I. Zenkevich and D. R. T. Zahn, Appl. Phys. A: Mater. Sci. Process., 2012, 107, 275-278.

36 T. Fang, W. Chang and C. Lin, Mater. Sci. Eng., A, 2007, 452, 715-720.

37 S. R. Jian, J. S. C. Jang, G. J. Chen, H. G. Chen and Y. T. Chen, J. Alloys Compd., 2009, 479, 348-351.

38 A. Roy, J. Mead, S. Wang and H. Huang, Sci. Rep., 2017, 7, 18.

39 S. S. Bhat, U. V. Waghmare and U. Ramamurty, Comput. Mater. Sci., 2015, 99, 133-137.

40 L. Liu, Y. Chen, T. Guo, Y. Zhu, Y. Su, C. Jia, M. Wei and Y. Cheng, ACS Appl. Mater. Interfaces, 2012, 4, 17-23.

41 X. Li, X. Wang, Q. Xiong and P. C. Eklund, Nano Lett., 2005, 5, 1982-1986.

42 D. Zhang, S. Chava, C. Berven, S. K. Lee, R. Devitt and V. Katkanant, Appl. Phys. A, 2010, 100, 145-150.

43 A. Baranowska-Korczyc, K. Fronc, Ł. Kłopotowski, A. Reszka, K. Sobczak, W. Paszkowicz, K. Dybko, P. Dłuzewski, B. J. Kowalski and D. Elbaum, RSC Adv., 2013, 3, 5656-5662. 44 T. P. Chen, S. P. Chang, F. Y. Hung, S. J. Chang, Z. S. Hu and K. J. Chen, Sensors, 2013, 13, 3941-3950.

45 J. Hupkes, J. I. Owen, S. E. Pust and E. Bunte, ChemPhysChem, 2012, 13, 66-73. 
46 A. Stafiniak, B. Boratyński, A. Baranowska-Korczyc, K. Fronc, D. Elbaum, R. Paszkiewicz and M. Tłaczała, J. Mater. Sci., 2013, 31, 312-317.

47 J. Zhou, N. Xu and Z. L. Wang, Adv. Mater., 2006, 18, 24322435.

48 A. Stafiniak, B. Boratyński, A. Baranowska-Korczyc, W. Mecherzyński, K. Fronc, R. Paszkiewicz, M. Tłaczała and D. Elbaum, J. Mater. Sci. Eng. B, 2012, 177, 1299-1303.

49 R. Ma, C. Levard, F. M. Michel, G. E. Brown and G. V Lowry, Environ. Sci. Technol., 2013, 47, 2527-2534.

50 Z. Pan, J. Tao, Y. Zhu, J. F. Huang and M. Parans Paranthaman, Chem. Mater., 2010, 22, 149-154.
51 T.-H. Huang, P.-K. Yang, D.-H. Lien, C.-F. Kang, M.-L. Tsai, Y.-L. Chueh and J.-H. He, Sci. Rep., 2014, 4, 4402.

52 A. Sirelkhatim, S. Mahmud, A. Seeni, N. H. M. Kaus, L. C. Ann, S. K. M. Bakhori, H. Hasan and D. Mohamad, Nano-Micro Lett., 2015, 7, 219-242.

53 V. B. S. Mallakpour, Eur. Polym. J., 2016, 84, 377-403.

54 G. Li, J. Zhai, D. Li, X. Fang, H. Jiang, Q. Dong and E. Wang, J. Mater. Chem., 2010, 20, 9215-9219.

55 V. K. Gupta, D. Pathania, M. Asif and G. Sharma, J. Mol. Liq., 2014, 196, 107-112. 